ORIGINAL ARTICLE

\title{
Post-Surgical Outcomes of Dorsolateral Onlay Urethroplasty
}

\author{
*CATM Mowladad ${ }^{1}, \mathrm{KM}_{\text {Rahman }}^{2}$, A Bakhtiar ${ }^{3}$ \\ H Rafiqul $^{4}$, R Shofiqur ${ }^{5}$, Faruquzzaman ${ }^{6}$ \\ $1 *$ Dr. Chowdhury ATM Mowladad, Department of Urology, BIRDEM General Hospital, Dhaka \\ ${ }^{2}$ Dr. Khan Mohiur Rahman, Department of Urology, BIRDEM General Hospital, Dhaka \\ ${ }^{3}$ Dr. Ahmed Bakhtiar, Department of Urology, BIRDEM General Hospital, Dhaka \\ ${ }^{4}$ Dr. Hassan Rafiqul, Department of Urology, BIRDEM General Hospital, Dhaka \\ ${ }^{5}$ Dr. Rahman Shofiqur, Department of Urology, BIRDEM General Hospital, Dhaka \\ ${ }^{6}$ Dr. Faruquzzaman Department of Urology, BIRDEM General Hospital, Dhaka \\ * Corresponding author
}

Date of submission: 04 May 2016

Date of acceptance: 20 June 2016

\begin{abstract}
Background: The standard management of urethral strictures involving the anterior urethra is dorsal onlay buccal mucosa augmentation urethroplasty. This requires circumferential mobilisation of the urethra, which might cause ischemia of the urethra in addition to chordee. In this research, we managed the anterior urethral stricture, applying a dorsolateral onlay urethroplasty.

Methodology: This prospective study was conducted in the Department of Urology, BIRDEM General Hospital\& some private hospitals from July 2009 to June 2015, the outcomes of a total cases of 103 of one sided anterior dorsolateral onlay OMG Urethroplastywere assess and compared. Patients with anterior and recurrent urethral stricture more than $1 \mathrm{~cm}$ were included as study population. Urethrogram and Uroflowmetry were the mainstay of assessment. Success was defined as a maximum flow rate of $>20 \mathrm{ml} / \mathrm{sec}$., normal RGU, and/or urethroscopy. Poor outcomes were defined as the presence of obstructive urinary tract symptoms, Qmax $<15 \mathrm{ml} / \mathrm{sec}$, , stricture diagnosed on retrograde urethrogram/ urethroscopy, and the need for any postoperative urethral intervention.

Result: Of the 103 patients, 97 had (94.2\%) successful outcome and $6(5.8 \%)$ were failure. Four failed cases underwent optical internal urethrotomy and two patients had persistent narrowing and they were managed by BMG Urethroplasty. Follow up period was 12 months on an average. In conclusion, it can be said thatthe preservation of one sided vascular supply to the urethra and its entire muscular and neurogenic support represent significantly towards perfecting the surgical technique of urethral reconstruction using a minimally invasive approach.
\end{abstract}

Conclusion: In this study, we found it to be a technically feasible, easily adoptable and finally successful procedure.

Key Words: Dorsolateral Onlay Urethroplasty, urethral strictures

\section{Introduction}

Management of anterior urethral stricture poses a continuing urological challenge. For the management of anterior urethral stricture, dorsal, ventral or lateral onlay urethroplasty may be employed as single-stage procedure $^{1 .}$ Out of these, dorsal onlay urethroplasty currently is the most favoured ${ }^{2}$. We performed dorsolateral onlay urethroplasty by unilateral urethral mobilisation ${ }^{3,4}$. In this technique the lateral vascular supply on one side is preserved, which minimiz esischemia. Since circumferential mobilisation of urethra is not carried out in this technique, there is less chances of developing ischemia with resultant chordee. Entire procedure is carried out by a perineal incision and no incision is made on the penis exceptmeatotomy. The pendulous urethra is accessed by penile eversion through the perineal wound. Obviating penile incisions minimise chances of wound infection and fistula formation. The preservation of the one-sided vascular supply to the urethra is perfecting the surgical technique of urethral reconstruction using a minimally invasive approach.Outcome of this technique was assess in this series. 


\section{Method And Material}

This prospective study was conducted in the department of urology, BIRDEM General Hospital and some other private hospitals from July 2009 to June 2015 having a total cases of 103 onlay OMG Urethroplasty. The age limit of the study population was 20 to 63 years. Patients with anterior and recurrent uretheral stricture more than 1 $\mathrm{cm}$ were included as study population. Patients with severe co-morbidity and soft stricture below $1 \mathrm{~cm}$ were excluded from the study group.

Preoperative evaluation included history, physical examination, urinalysis, ultrasonography of KUB region with post-voided residual, retrograde \&micturatingcy stourethrography and Uroflowmetry.

An intra-operative urethroscopy was performed to evaluate the caliber of the urethra and stricture. We performed the dorsolateral onlay procedure only when a guide wire could be negotiated through the non obliterative stricture segment. Urethroplasty was performed in perineal approach, with the patient in high lithotomy position.

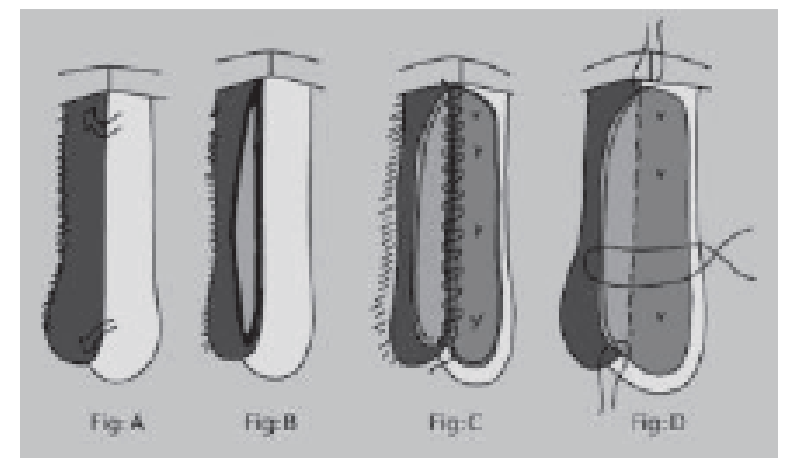

Figure 1: (A) Mobilization of urethra beyond midline dorsally, (B) Dorsal uethrotomy, (C) Graft sutured to medial urethral margin, (D) Free margin of the graft sutured to lateral urethral margin.

The penis was everted through the perineal incision. The urethra was mobilized from left side of the ventralaspect to beyond the midline on the dorsal aspect[Figure 1A]. Fascia and vascular attachments on theother side of the urethra were left intact. Maximum distaland proximal limits of dissection were meatus andbulbomembranous junction. Urethrotomy was made inthe midline dorsally [Figure 1B].

Oral mucosa at least 1:1 ratio to be incised urethral plate was harvested.One edge of the graft was sutured to the margin, was fixed to thecorpora [Figure 1C]. A 16Fr Foleys catheter waskept. The other margin of the graft was sutured to thelateral margin of the urethra and the tunica of corpora [Figure 1D]. Graft was placed unstretched to prevent chordee. The bulbospongiosus musclewas approximated in the midline in case of involvement of bulbar urethra.

The catheter was left in situ for 2-3 weeks. The patient was ambulated on the first postoperative dayand was discharged from the hospital 3-5 days aftersurgery. All patients received broad-spectrum antibioticsand were maintained on oral preparation till removal of catheter. All patients were followed at 3, 6, 9, and 12 months postoperatively. At every visit, patients were assessed for symptoms, urine culture \& sensitivity, ultrasound to assess post void residual urine and uroflowmetry. The average follow up period of study population was 12 months.

Table 1: Grading of postoperative outcomes

\begin{tabular}{clll}
\hline & GOOD (A) & FAIR (B) & POOR(C) \\
\hline $\begin{array}{clll}\text { Patient } \\
\text { satisfaction }\end{array}$ & $\begin{array}{l}\text { Satisfactory } \\
\text { voiding, no } \\
\text { instrumentation } \\
\text { required }\end{array}$ & $\begin{array}{l}\text { Satisfactory } \\
\text { voiding, } \\
\text { but require } \\
\text { OIU }\end{array}$ & $\begin{array}{l}\text { Not } \\
\text { satisfactory; } \\
\text { require BMG } \\
\text { urethroplasty }\end{array}$ \\
Uroflometry & $\begin{array}{l}\text { Q max }>20 \\
\mathrm{ml} / \mathrm{sec}\end{array}$ & $\begin{array}{l}\text { Qmax 15-20 } \\
\mathrm{ml} / \mathrm{sec}\end{array}$ & $\begin{array}{l}\text { Qmax }<15 \\
\mathrm{ml} / \mathrm{sec}\end{array}$ \\
Retrograde & Good caliber & $\begin{array}{l}\text { Partial } \\
\text { narrowing } \\
\text { at stricture } \\
\text { Site }\end{array}$ & $\begin{array}{l}\text { Persistent } \\
\text { stricture }\end{array}$ \\
\hline
\end{tabular}

The results were classified into the following outcomes.Success was defined as a maximum flow rate of $>20 \mathrm{ml} / \mathrm{sec}$., normal RGU, and/or urethroscopy. Poor outcomes were defined as the presence ofobstructive urinary tract symptoms, Qmax $<15 \mathrm{ml} / \mathrm{sec}$, stricture diagnosed on retrograde urethrogram/urethroscopy, and the need for any postoperative urethralintervention (Table I).

Data were processed and analyzed using SPSS (Statistical Package for Social Sciences) software. The test statistics used to analyze the data were descriptive statistics, Chisquare test, and Student's t-Test. For all analytical tests, the level of significance was set at 0.05 and $p<0.05$ was considered significant.

\section{Result}

The age of the patients range from 20 to 63 years with mean age of 39.3 years. The age distribution with preoperative characteristics of the study population is defined in table 2. 
Table 2: Preoperative evaluation

\begin{tabular}{|c|c|c|c|c|}
\hline $\begin{array}{c}\text { Age } \\
\text { (in years) }\end{array}$ & $\begin{array}{c}\text { Length of } \\
\text { stricture }(\mathrm{cm})\end{array}$ & $\begin{array}{c}\text { RGU/MCU-site } \\
\text { of stricture }\end{array}$ & $\begin{array}{c}\text { Uroflow } \\
\text { metry } \\
\text { Qmax } \\
\text { (mL/sec) }\end{array}$ & $\begin{array}{c}\text { USG } \\
\text { KUB/PVR } \\
(\mathrm{mL})\end{array}$ \\
\hline R: $20-63$ & R: 2.4-11.66 & Bulbar: 33 & R: $3-10$ & $\mathrm{R}: 120-200$ \\
\hline M: 39.3 & M: 6.9 & $\begin{array}{c}\text { Penobulbar: } 43 \\
\text { Penile: } 27\end{array}$ & M: 6.08 & M: 145.25 \\
\hline
\end{tabular}

\section{R: range, M: mean}

Mean length of stricture was $6.9 \mathrm{~cm}$ with standard deviation 3.84. Most of the strictures (41.7\%) were present in both bulbar and penile urethra, 27 (26.2\%) patients had in penile urethra and 33 (32.1\%) had in bulbar urethra. The most common presentation was poor flow. The etiology of the stricture was infection (41.25\%), followed by balanitis xerotica obliterans $(26.25 \%), 17.5 \%$ was idiopathic and $15 \%$ was iatrogenic urethral trauma due to instrumentation. During post-operative follow up six $(5.8 \%)$ patients developed wound infection. Mean preoperative Qmax was $6.08 \mathrm{ml} / \mathrm{sec}$ and mean postoperative Qmax was $29.8 \mathrm{ml} / \mathrm{sec}$. Paired t test was done and showed the difference was statistically significant ( $p$ value was $<0.001$ ) at the end of last follow up. Pre operatively sonography showed average post voided residual volume was $145.25 \mathrm{ml}$ which was significantly high. But post operatively majority of the patients $97(94.2 \%)$ did not show any significant PVR. Operative time was 1.5 hours to 2.5 hours.

Table 3: Mean Value of Peak flow rate following urethroplasty at the end of follow up period

\begin{tabular}{ccc}
\hline $\begin{array}{c}\text { Pre and } \\
\text { postoperative } \\
\text { peak flow rate }\end{array}$ & Mean \pm SD & P value \\
\hline Preoperative and & $6.08 \pm 1.95$ & $0.001^{\mathrm{S}}$ \\
1 month postoperative & $29.78 \pm 3.06$ & \\
Preoperative and & $6.08 \pm 1.95$ & $0.001^{\mathrm{S}}$ \\
3 month postoperative & $30.02 \pm 3.13$ & \\
Preoperative and & $6.08 \pm 1.95$ & $0.001^{\mathrm{S}}$ \\
6 month postoperative & $29.06 \pm 2.80$ & \\
Preoperative and & $6.08 \pm 1.95$ & $0.001^{\mathrm{S}}$ \\
9 month postoperative & $28.60 \pm 2.40$ & \\
Preoperative and & $6.08 \pm 1.95$ & $0.001^{\mathrm{S}}$ \\
12 month postoperative & $29.04 \pm 2.77$ & \\
\hline
\end{tabular}

Table 4: Outcome of Urethroplasty after completion of 12 months follow up

\begin{tabular}{|c|c|c|c|c|}
\hline & Patient satisfaction & Uroflowmetry & $\begin{array}{l}\text { RGU with } \\
\text { MCU }\end{array}$ & $\begin{array}{c}\text { Number of } \\
\text { patients }\end{array}$ \\
\hline $\begin{array}{l}\text { GOOD } \\
\text { (A) }\end{array}$ & $\begin{array}{l}\text { Satisfactory } \\
\text { voiding, no } \\
\text { nstrumentation } \\
\text { required }\end{array}$ & $\mathrm{Q} \max$ & Good caliber & 97 \\
\hline $\begin{array}{l}\text { FAIR } \\
\text { ( B ) }\end{array}$ & $\begin{array}{l}\text { Satisfactory } \\
\text { voiding, but } \\
\text { requirøptical } \\
\text { internal urethrotomy }\end{array}$ & $\begin{array}{c}\text { Qmax } \\
15-20 \mathrm{ml} / \mathrm{sec}\end{array}$ & $\begin{array}{l}\text { Partial } \\
\text { narrowing } \\
\text { at stricture } \\
\text { site }\end{array}$ & 04 \\
\hline $\begin{array}{l}\text { Poor } \\
\text { (C) }\end{array}$ & $\begin{array}{c}\text { Nonsatisfactory, } \\
\text { required OMG } \\
\text { urethroplasty. }\end{array}$ & $\begin{array}{c}\text { Qmax } \\
<15 \mathrm{ml} / \mathrm{sec}\end{array}$ & $\begin{array}{l}\text { Persistent } \\
\text { stricture }\end{array}$ & 02 \\
\hline
\end{tabular}

97 patients were satisfied with surgery and had Qmax $>20$ $\mathrm{ml} / \mathrm{sec}$. Four patients had narrowing at graft site and voided with poor stream. We managed above patients with optical internal urethrotomy. Two patients had persistent narrowing and they were managed by BMG Urethroplasty.

\section{Discussion}

In the dorsal onlay technique, the conventional circumferential dissection of the whole anterior urethra risks the vascularity of the urethra, which may be more important if the meatus is involved with disease and the distal-most urethra is extensively dissected, such as is seen with concomitant balanitis xerotica obliterans. The Barbagli procedure with circumferential mobilization of the urethra for dorsal onlay patch has a success rate of $99 \%$ and $66 \%$ in the short- and long-term, respectively ${ }^{5}$. However, in long segment anterior urethral strictures, circumferential urethral mobilization may jeopardize the lateral vascularity of the urethra. Barbagli also described the lateral onlay procedure with results similar to dorsal and ventral onlay for bulbar urethral strictures ${ }^{6}$. In the pendulous urethra, ventral and lateral onlay grafts have the risk of diverticulum formation.

Asopa's procedure of inlay patch by ventrally incising the urethra is another option for anterior urethral strictures ${ }^{7}$. It preserves the lateral vascularity of the urethra. However, it has two potential drawbacks. Firstly, a wider graft may be difficult to be placed using this approach and may likely get folded. Secondly, we do not know how the long ventral sagittal incision on the scarred urethra will behave in the long-term follow-up. In the short-term follow-up, this procedure has shown good results ${ }^{7,8}$. Singh, et al., have shown the superiority of the Asopa 
procedure $(86 \%)$ over the Barbagli procedure $(66 \%)$ in terms of success and complications ${ }^{9}$. This also supports the approach of restricting the mobilization of the urethra from its bed in patch urethroplasties for long segment anterior urethral strictures.

To maintain the urethral vascularity on one side of the urethra while keeping the graft in a dorsolateral onlay fashion, we adopted the technique of Kulkarni. Technically, it is as easy as the Barbagli procedure. It also preserves the one-sided bulbar artery in addition to maintaining the native lateral vascularity at the meatus and the distal urethra. Furthermore, by using this approach, we did not find postoperative chordee in any case. In this procedure, the urethra is not completely mobilized off the corpora; hence, graft sizing is more appropriate, preventing the chordee. In our study, during postoperative follow up, six patients $(5.8 \%)$ developed wound infection\& subsequent urethral stricture. Four were managed by OIU and two were managed by OMG Urethroplasty. Regarding post-operative patients' compliance, it was found in this research study that 97 (94.2\%) patients were satisfied with surgery.

In a research study by Shah et al ${ }^{10}$ it was reported that $7.5 \%$ was associated with poor post-surgical outcomes, with an overall success rate of approximately over $90 \%$.Songraet $\mathrm{al}^{11}$ (2005) reported overall success rate was $85.71 \%$ and only 2 patients had re-stricture out of 14 patients. Iselin \& Webster ${ }^{12}$ in their series of 29 men who underwent dorsal onlay graft urethroplasty reported a high early success rate of $97 \%$ at a median follow-up of 19 months. Study on One sided anterior Urethroplasty by Kulkarni et al ${ }^{13}$ shows study on 24 patients with mean follow up of 22 months shows $22(92 \%)$ had a successful outcome and two (8\%) were failures.In our study, mean preoperative Qmax was $6.08 \mathrm{ml} / \mathrm{sec}$ and mean postoperative Qmax was $29.04 \mathrm{ml} / \mathrm{sec}$. In the study by Singh et al9 (2009) mean preoperative Qmax was 6.7 $\mathrm{ml} / \mathrm{sec}$ (Range 3.8 - 9.5) and mean postoperative Qmax was $16.4 \mathrm{ml} / \mathrm{sec}$ (Range 8-21.2). So, the result is well comparable to other studies.

\section{Conclusion}

The preservation of one sided vascular supply to the urethra and its entire muscular and neurogenic support represent significantly towards perfecting the surgical technique of urethral reconstruction using a minimally invasive approach. In this study, we found it to be a technically feasible, easily adoptable and finally successful procedure.

\section{Conflict of interest: none}

\section{Reference}

1. Barbagli G, Palminteri E, Guazzoni G, et al. Bulbar urethroplasty using buccal mucosa grafts placed on the ventral, dorsal or lateral surface of the urethra: Are results affected by the surgical technique? J Urol. 2005; 174: 955-7. discussion 957-8.

2. Patterson JM, Chapple CR. Surgical techniques in substitution urethroplasty using buccal mucosa for the treatment of anterior urethral strictures. EurUrol 2008; 53:1162.

3. Singh BP, Pathak HR, Andankar MG. Dorsolateral onlay urethroplasty for anterior urethral strictures by a unilateral urethral mobilization approach. Indian J Urol 2009; 25: 211-14 .

4. Kulkarni S, Barbagli G, Sansalone S, et al. One-sided anterior urethroplasty: a new dorsal onlay graft technique. BJU Int 2009; 104: 1150-55.

5. Barbagli G, Morgia G, Lazzeri M. Dorsal onlay skin graft bulbar urethroplasty: Long-term follow-up. Eur Urol. 2008; 53: 628-33.

6. Barbagli G, Palminteri E, Guazzoni G, et al. Bulbar urethroplasty using buccal mucosa grafts placed on the ventral, dorsal or lateral surface of the urethra: Are results affected by the surgical technique? J Urol. 2005; 174: 955-7. discussion 957-8.

7. Asopa HS, Garg M, Singhal GG, et al. Dorsal free graft urethroplasty for urethral stricture by ventral sagittal urethrotomy approach. Urology. 2001; 58: 657-9.

8. Pisapati VL, Paturi S, Bethu S, Jada S, Chilumu R, Devraj $R$, et al. Dorsal buccal mucosal graft urethroplasty for anterior urethral stricture by asopa technique. EurUrol 2008 Jun 9. 2008 Jun 9.

9. Singh PB, Das SK, Kumar A, et al. Dorsal onlay lingual mucosal graft urethroplasty: Comparison of two techniques. Int J Urol. 2008; 15: 1002-5.

10. Shah SA, Ranka P, Choudhary R, et al. Buccal mucosal dorsal substitution urethroplasty in recurrent anterior urethral stricture. Indian J Urol 2003; 19: 152-6.

11. Songra MC, Kerketta A, Dua R. Single stage substitution urethroplasty using buccal mucosal graft in management of stricture urethra. Indian J Urol 2005; 23(2): 115-9.

12. Iselin CE, Webster GD. Dorsal onlay graft urethroplasty for repair of bulbar urethral stricture. J Urol 1999; 161: 815-818.

13. Kulkarni BS, Barbagli G, Sansalone S, et al. Onesided anterior urethroplasty: a new dorsal onlay graft technique. BJUI 2009; 1-6. 